\title{
Knowledge and Adoption of Paddy Cultivation Practices in Hosanagara Taluk of Shivamogga District
}

\author{
Mohammad Emran ${ }^{1 *}$, M. Sudheendra ${ }^{1}$, S. Sahana ${ }^{1}$, \\ Sarvajna B. Salimath ${ }^{2}$ and H. B. Mallikarjuna ${ }^{3}$
}

${ }^{1}$ Department of Agricultural Extension, ${ }^{2}$ Department of Soil Science and Agricultural Chemistry, ${ }^{3}$ Department of Agricultural Statistics, College of Agriculture, University of Agricultural and Horticultural Sciences, Shivamogga, Karnataka, India

*Corresponding author

\section{A B S T R A C T}

\section{Keywords}

Knowledge and Adoption levels of paddy cultivation farmers

\section{Article Info}

Accepted:

15 August 2020 Available Online: 10 September 2020
The study was conducted in Hosanagara taluk of Shivamogga district in Karnataka state during the year 2019-20 to study the knowledge and adoption of paddy cultivation practices of farmers in paddy crop. A total of 120 respondents were randomly selected based on paddy cultivation area. Farmers were personally interviewed using a pre-tested interview schedule. Majority of the paddy farmers had medium $(64.17 \%)$ to high $(18.33 \%)$ knowledge level on paddy cultivation. More than half of respondents had medium (59.17\%) to high $(23.33 \%)$ adoption level with respect to paddy cultivation practices. Hence, there is a necessity to provide training programmes through KVKs and Agricultural Department for the improvement of paddy cultivation methods to the farmers in order to enhance their knowledge and adoption levels of paddy production technology.

\section{Introduction}

The slogan "RICE is life" is most appropriate for India as this crop plays a vital role in our food security as national and is a means of livelihood for millions of households. It provides between 35.00 to 60.00 per cent of the dietary calories consumed by nearly more than 3 billion populations. Rice fulfills 43 per cent of calories requirement of more than 70.00 per cent of the Indian population majorly relay on this staple food. Globally, it is also the second most cultivated cereal after wheat. Area under rice in India is 42.9 million-hectare with a production of 112.9 million tonnes and productivity of 2,585 $\mathrm{kg} / \mathrm{ha}$ (India stat, 2018).

In Karnataka the Rice is cultivated in diverse climatic condition. Paddy area in 2015-16 was 1.11 million-hectare, and 3.21 million tonnes of production. whereas $2,722 \mathrm{~kg} / \mathrm{ha}$ is productivity, Shivamogga district comes under medium productive region having an area of about 1.29 lakh ha and production of 3.13 lakh tonnes with productivity of 2,516 
$\mathrm{kg} / \mathrm{ha}$ (Database of Area under principal crops, Directorate of Agricultural Economics and Statistics, 2017).

In Hosanagara taluk area under paddy cultivation is 9,734 hectares, production of about 28,469 tonnes and around 2,700 kg/ha productivity having was purposefully selected for the present study. As it come under hilly zone. (Agriculture office of Hosanagara taluk, 2019)

The main objective of this study includes to study the knowledge level of farmers about paddy cultivation. And also to study the extent of adoption of production technology in paddy cultivation.

Umeh and Chukwu (2013) with their findings from the study on determinants of adoption of improved rice production technologies in ebonyi state of Nigeria, revealed that majority $(91.67 \%)$ of the rice farmers are knowledgeable on availability and use of improved rice varieties.

Singh et al., (2014) showed that majority of the respondents $(45.00 \%)$ had medium level of knowledge, followed by 33.33 per cent who had high level of knowledge and it was observed that 21.67 per cent had low level of knowledge.

Kumari (2015) studied on impact of front line demonstration on area and productivity of wheat growers in Jabalpur district (M.P.), reported that majority of the FLD beneficiaries $(76.00 \%)$ were having high knowledge of wheat production technology. Whereas majority of non- FLD beneficiaries (44.00\%) were having medium knowledge of wheat production technology.

Nagaraj et al., (2015) observed that majority $(42.50 \%)$ of paddy farmers had a medium level of the adoption, followed by low
$(32.50 \%)$ and high $(25.00 \%)$ levels of the adoption. Visalakshi and Sireesha (2016) indicated that $(40.00 \%)$ of FLD farmers had high level of adoption followed by medium $(36.00 \%)$ and low $(24.00 \%)$ levels of adoption. (40.00\%) of non-FLD farmers had medium level of adoption followed by high $(32.00 \%)$ and low (28.00\%) levels of adoption.

Venkata Rao et al., (2016) reported that majority $(52.00 \%)$ of the paddy farmers had a medium level of adoption, followed by high $(28.00 \%)$ and low (14.00\%) levels of adoption.

\section{Materials and Methods}

The research methodology must have a theoretical orientation for its success. The present study was conducted during the year 2019-20. The study was conducted in Hosanagara taluka of Shivamogga district. Four hoblis were selected based on highest acreage on paddy cultivation. From each hobli three villages were selected based on the highest area under paddy cultivation. From each village 10 paddy farmers were randomly selected. Thus from 12 villages, a total of 120 respondents were selected.

\section{Knowledge}

The knowledge is operationalized as the information, experience or familiarity about programme, usage, interventions and consequences gained through experience, learning or adoption

To measure knowledge suggested by Anastasi (1961) was employed to measure the knowledge level of respondents. Paddy cultivation practices were listed separately in consultation with the experts. The questions and answers were carefully framed. The answers elicited from the farmers were 
quantified by giving ' 1 ' score to correct and ' 0 ' to wrong answers.

Total (30) knowledge questions framed the respondents have the chance to score maximum score of (30) and minimum score of ' 0 ' relating this total score calculated.

Based on the respondents option for each statement frequency and percentage were calculated to expire item wise knowledge, the overall knowledge of the respondents was expired low, medium, and high knowledge by taking mean and standard division as a measure of a check. Results were expiring in frequency and percentage.

\section{Adoption}

Adoption is a decision to make full use of an innovation as the best course of action available. In this study, it refers to the adoption level of paddy technology were listed.

A total of 30 statements from land preparation up to harvesting were listed by consulting with experts, the responses were quantified by giving 1 and 0 scores for adopted and not adopted respectively for each of the practice. Thus, the maximum score of the respondent could be optimum was 30 and the minimum score was zero.

Based on respondents for each statement frequency and percentage were calculated to expire items of adoption, the overall adoption of the respondents was grouped into three as low, medium, and high by using mean and standard deviation as a measure of the check. Results were expiring by the frequency and percentage.

\section{Results and Discussion}

The results of present research study have been presented on the basis of analysis of data using suitable statistical tools and techniques and in relation to the specific objective of the research study.

\section{Overall knowledge level of farmers on paddy cultivation practices}

Table 1 shows that majority of the respondents $(64.17 \%)$ had medium overall level of knowledge, followed by 18.33 per cent of the respondents had high level of knowledge and 17.50 per cent of the farmers belonged to low level of knowledge. The possible reason might be due to their higher literacy level, of the respondents had medium land holdings with medium extension contact, medium innovativeness and medium risk orientation. This would have motivated them to gain more knowledge on Paddy cultivation practices. The agricultural department and extension agencies should conduct training programmes on Paddy cultivation practices farmers visit to demonstration plots, progressive farmer's fields and inspiring them to have more extension contact, extension participation and social participation. So that these farmers will improve their knowledge about recommended package of practices. Similar findings were reported by Meena et al., (2012).

\section{Knowledge level of farmers on different paddy cultivation practices}

Table 2 indicated that majority $(83.33 \%)$ of the respondents were found to have correct knowledge about variety of paddy, due to the fact that the farmers have medium extension contact they might have got technical experts for advice. Majority (77.50\%) of the respondents have knowledge about spacing between lines and rouging practice. Majority (75.00\%) of the respondents have knowledge about irrigation and annual rainfall, due to the fact that famers knows about time of the irrigation and also the area more rainfall during season the make storage of the water 
for irrigated. Majority $(73.33 \%)$ of the respondent have knowledge about yield of paddy, due to the fact that farmers' growth high yield varieties for the production. Majority $(69.17 \%)$ of the respondents have knowledge about harvesting and threshing, due to the fact that the farmers have got the product on time. Majority $(63.33 \%)$ of the respondent have knowledge about seed rate and seed treatment, due to the fact that the farmers have general knowledge regarding the paddy seed and treatment. More than half $(55.83 \%)$ of the respondents have knowledge about the duration of the crops, due to knowing the farmers' specific duration time of the crop from the sowing up to harvesting. Less than half $(49.17 \%)$ the respondents have knowledge about fertilizer, due to the fact that farmers used the more fertilizer for the production and productivity of crop and also less than half $(46.67 \%)$ the respondents have less knowledge about the transplanting of seedling, due to the fact that the farmers needed training regarding the information from Agriculture department, KVKs and the University.

\section{Overall adoption level of the farmers on paddy cultivation practices}

The findings of the present study are also in line with this fact with respect to adoption of improved paddy varieties practices by the respondents which are presented in Table 3 indicated that 59.17 per cent came under medium adopter category followed by 23.33 per cent of the respondents belonged to high adoption category. Majority of the respondents represent the medium to high adoption since most of them have adopted the practices like land preparation, proper seed rate/seed treatment, transplanting, nutrient management, weed management, rouging and harvesting / post-harvest operations etc. The obtained results may be due to the fact that, if the farmers did not adopt these paddy practices, there is a chance of rejection due to low quality.

Least percentage of respondents 17.50 per cent belonged to low overall adoption level. This could be due to lack of proper knowledge on some paddy practices, lack of technical guidance could be the reason for non-adoption, even though farmers had enough knowledge, difficulty in adopting some practices like maintaining isolation distance from other field and lack of contact with extension personnel might have resulted in lower overall adoption level of improved paddy varieties farmers with respect to some of the paddy practices. Similar findings were reported by Nirmala et al., (2013).

\section{Activity wise adoption level of paddy cultivation practices by the farmers}

Table 4 shows that different adoption levels such as full adoption and non-adoption, as per individual recommended of paddy cultivation practices. The results are presented practice wise in the following

The results further reveal that majority (90.83\%) of the respondents got good yield of paddy. They followed recommended harvesting and post harvesting practices $(85.83 \%)$, land preparation $(83.33 \%)$, recommended the transplanting of seedling (80.00 \%), recommended applied nutrient management $(77.50 \%)$, recommended quantity of seed rate and seed treatment $(68.33 \%)$, recommended disease and pest $(67.50 \%)$, recommended weed management $(58.33 \%)$ and recommended rouging at different stages of crop $(45.83 \%)$. 
Table.1 Overall knowledge level of farmers on paddy cultivation practices $(n=120)$

\begin{tabular}{|c|l|c|c|c|}
\hline Sl. No & \multicolumn{1}{|c|}{ Category } & Criteria & Frequency & Percentage \\
\hline $\mathbf{1}$ & Low & Less than (Mean -SD) & 21 & 17.50 \\
\hline $\mathbf{2}$ & Medium & Between (Mean \pm SD) & 77 & 64.17 \\
\hline $\mathbf{3}$ & High & More than (Mean + SD) & 22 & 18.33 \\
\hline \multicolumn{2}{|c|}{ Total } & 120 & $\mathbf{1 0 0}$ \\
\hline & \multicolumn{2}{|c|}{ Standard deviation=2.64 } \\
\hline
\end{tabular}

Table.2 Knowledge level of farmers on different paddy cultivation practices $(n=120)$

\begin{tabular}{|c|l|c|c|}
\hline SI. No. & Statements & Frequency & Percentage \\
\hline $\mathbf{1}$ & Variety of paddy & 100 & 83.33 \\
\hline $\mathbf{2}$ & Seed rate and seed treatment & 76 & 63.33 \\
\hline $\mathbf{3}$ & Transplanting of seedling & 56 & 46.67 \\
\hline $\mathbf{4}$ & Spacing and rouging & 93 & 77.50 \\
\hline $\mathbf{5}$ & Irrigation and rainfall & 90 & 75.00 \\
\hline $\mathbf{6}$ & Application of Fertilizer & 59 & 49.17 \\
\hline $\mathbf{7}$ & Plant protection & 71 & 59.17 \\
\hline $\mathbf{8}$ & Duration of the crop & 67 & 55.83 \\
\hline $\mathbf{9}$ & Harvesting and trashing & 83 & 69.17 \\
\hline $\mathbf{1 0}$ & Yield of production & 88 & 73.33 \\
\hline $\mathbf{1 1}$ & Market and storage & 70 & 58.33 \\
\hline
\end{tabular}

Table.3 Overall adoption level of the farmers on paddy cultivation practices. $(n=120)$

\begin{tabular}{|c|c|c|c|c|}
\hline Sl. No & Category & Criteria & Frequency & Percentage \\
\hline 1 & Low & Less than (Mean -SD) & 21 & 17.50 \\
\hline 2 & Medium & Between $($ Mean \pm SD) & 71 & 59.17 \\
\hline 3 & High & More than $($ Mean + SD) & 28 & 23.33 \\
\hline \multicolumn{3}{|c|}{ Total } & 120 & 100 \\
\hline & Mean=24.15 & \multicolumn{3}{|c|}{ Standard deviation $=2.72$} \\
\hline
\end{tabular}

Table.4 Activity wise adoption level of paddy cultivation practices by the farmers. $(n=120)$

\begin{tabular}{|c|l|c|c|}
\hline Sl. No. & \multicolumn{1}{|c|}{ Statements } & Frequency & Percentage \\
\hline $\mathbf{1}$ & Land preparation & 100 & 83.33 \\
\hline $\mathbf{2}$ & Seed rate and Seed treatment & 82 & 68.33 \\
\hline $\mathbf{3}$ & Transplanting method & 96 & 80.00 \\
\hline $\mathbf{4}$ & Nutrient management & 93 & 77.50 \\
\hline $\mathbf{5}$ & Weed management & 70 & 58.33 \\
\hline $\mathbf{6}$ & Rouging practices & 55 & 45.83 \\
\hline $\mathbf{7}$ & Pest and Disease & 81 & 67.50 \\
\hline $\mathbf{8}$ & Harvesting and Post harvesting & 103 & 85.83 \\
\hline $\mathbf{9}$ & Yield of production & 109 & 90.83 \\
\hline
\end{tabular}


The reason for their poor adoption may be due to lack of technical guidance on those above paddy cultivation practices, a part from requiring costly inputs and difficulty in adopting some paddy practices. Karnataka state Department of Agriculture and universities should have organise need based skill oriented training programmes especially through KVKs and other institutes to hasten up the adoption of these cultivation practices.

In conclusion the present study revealed that maximum number of farmers had sufficient knowledge on the various paddy practices i.e, from land preparation to the final harvesting of the paddy crop. However, the few farmers had limited knowledge on the specific paddy cultivation practices. Hence, concerned authorities like KVK's and Agricultural line department should encourage the farmers by disseminating timely and relevant information which results in enhancing their knowledge level on paddy cultivation practices and also through appropriate extension methods can foster the better adoption of the new practices. The farmers have adopted recommended practices such as land preparation up to harvesting stage. While, few farmers have not adopted the practices. Hence, Universities, Agricultural department, KVK's and other institutes have the responsibility to motivate the farmers to better adoption of the cultivation practices leading to the better income in turn improved standard of living of the paddy farmers.

\section{References}

Anastasi, A., 1961. Psychological testing The Mcmillan Co. New York. pp 45

Directorate of Agricultural Economic and Statistices., 2017. Area under principle crops. Retrieved from http://www.deskar.nic.in/http://www.i ndiastat.comhttp://www.ricepedia.com India Agristat., 2018. Rice commodity profile of India. 3/2018. Retrieved from http://www.agricoop.gov.in/sites/defau lt/files/Rice\%20profile\%20March\%2C $\% 2 \mathrm{C} \% 202018 . \mathrm{PDF}$

Kumari K., 2015. A study on impact of front line demonstration on area and productivity of wheat growers in Jabalpur district (M.P.). Thesis J.N.K.V.V., Jabalpur.

Meena, S.L., Lakhera, J.P., Sharma, K.C and Johri Raj S.K., 2012. Knowledge level and adoption pattern of rice production technology among farmers. Indian Raj. J. Extn. Edu. 20: 133-137.

Nagaraj, P. S., Dhananjaya Sawamy, A., Madhushree S. N., and Hanchinal., 2015. Extent of adoption of farm mechanization practices by the paddy growers in Tungabhadra project area, Karnataka, Indian journal of social research. 56(2): 256-270.

Nirmala, B., Vasudev, N and Suhasini., 2013. Farmer's Perceptions on Hybrid Rice Technology: A Case Study of Jharkhand. Indian Res. J. Ext. Edu., 13(3):103-105.

Singh, D. P., Yadav, S. K and Aijrhass., 2014. Knowledge and Adoption gap of Tribal farmers of Bastar towards Rice Production Technology. American International Journal of Research in Humanities, Arts and Social Sciences. (54).

Umeh, G.N and Chukwu. V.A., 2013. Determinants of adoption of improved rice production technologies in ebonyi state of Nigeria. International Journal of Food, Agriculture and Veterinary Sciences. 3(3): 126-133.

Venkata Rao, P., Neelaveni, S., Pradeep Kumar, P. B. and Punna RAO, P., 2016. Constraint analysis of drum seeder technology in paddy cultivation in North coastal Zone of Andhra Pradhra Pradesh. The Andhra Agricultural journal. 63(2): 457-460. 
Visalakshi, $M$ and Sireesha, A., 2016. Rice using drum seeder. Journal of Adoption Status of Direct Seeding Rice Research. 9(1): 30-34.

\section{How to cite this article:}

Mohammad Emran, M. Sudheendra, S. Sahana, Sarvajna B. Salimath and Mallikarjuna, H. B. 2020. Knowledge and Adoption of Paddy Cultivation Practices in Hosanagara Taluk of Shivamogga District, India. Int.J.Curr.Microbiol.App.Sci. 9(09): 1666-1672.

doi: https://doi.org/10.20546/ijcmas.2020.909.207 